\title{
Duplication of the right vertebral artery: MRA findings and review of the literature
}

\author{
Jiyeon Baik ${ }^{1}$, Hye Jin Baek ${ }^{2 *}$, Hwa Seon Shin ${ }^{3}$ and Kwang Ho Choi ${ }^{4}$
}

\begin{abstract}
Introduction: Duplication of the vertebral artery (VA) is a rare vascular variant. To the best our knowledge, only fourteen cases have been reported with angiographic findings that they have dual origin of the VA from ipsilateral subclavian artery. Herein, we present a case of duplication of right VA which was incidentally detected by magnetic resonance (MR) angiography.

Case description: A 69-year-old female patient presented with headache for 30 days. She underwent brain MR imaging with MR angiography for evaluating possible intracranial cause. There was a dual origin of the right vertebral artery (VA) as an incidental finding without other significant abnormalities.

Discussion and Evaluation: Diagnosis of duplicated VA can be difficult due to its rarity and misinterpreted as the vascular dissection. In addition, a detailed knowledge of this variation is potentially important to prevent inadvertent challenges during endovascular procedure. Because duplicated VA has smaller lumen and usually enters the higher transverse foramen than those of normal side, it can be influence the choice or route of endovascular treatment.

Conclusions: We suggested that the understanding of embryologic background about VA can be helpful to identify unexpected vascular findings on imaging studies in clinical practice.
\end{abstract}

Keywords: Duplication, Vertebral artery, Magnetic resonance angiography

\section{Background}

Duplication of vertebral artery (VA) is rare and represents $0.72 \%$ in autopsy studies (Bergman et al. 1988). This vascular variant is considered a developmental anomaly that shows a dual origin with a variable level of fusion in the neck (Goddard et al. 2001). According to previous articles, there are 36 reported cases about this vascular variant (Komiyama et al. 1999; Watanabe et al. 2015). However, a total of 14 cases have been reported with angiographic findings in literature that they have dual origin of the VA from ipsilateral subclavian artery (SCA), including a case of bilateral VA duplications. It is clinically significant because it can be mistaken for a dissection of VA (Thomas et al. 2008). Herein, we present a case of duplication of VA as an incidental finding during magnetic resonance

\footnotetext{
*Correspondence: sartre81@gmail.com

${ }^{2}$ Department of Radiology, Gyeongsang National University School of Medicine and Gyeongsang National University Changwon Hospital, 11 Samjeongja-ro, Seongsan-gu, Changwon 51472, Republic of Korea Full list of author information is available at the end of the article
}

angiography (MRA) examination of a patient with headache. Further, we also reviewed its embryological mechanism and clinical significance of this variation.

\section{Case description}

A 69-year-old female patient presented with headache for 30 days. She had no other clinical manifestation or significant past medical history. There was no abnormal finding at the initial neurological examination.

She underwent cranial magnetic resonance image (MRI) with 3D time-of-flight (TOF) intracranial MRA and gadolinium-enhanced neck MRA, using $1.5 \mathrm{~T}$ system (Signa Excite, GE Medical Systems, Milwaukee, WI, USA). Routine cranial MR images revealed no significant focal lesion in the brain parenchyma. 3D TOF intracranial MRA was also normal. Contrast-enhanced neck MRA demonstrated a duplication of the right VA with two origins from ipsilateral SCA before the origin of right internal thoracic artery (Fig. 1). The two limbs of duplicated VA confined to proximal V1 segment, and 


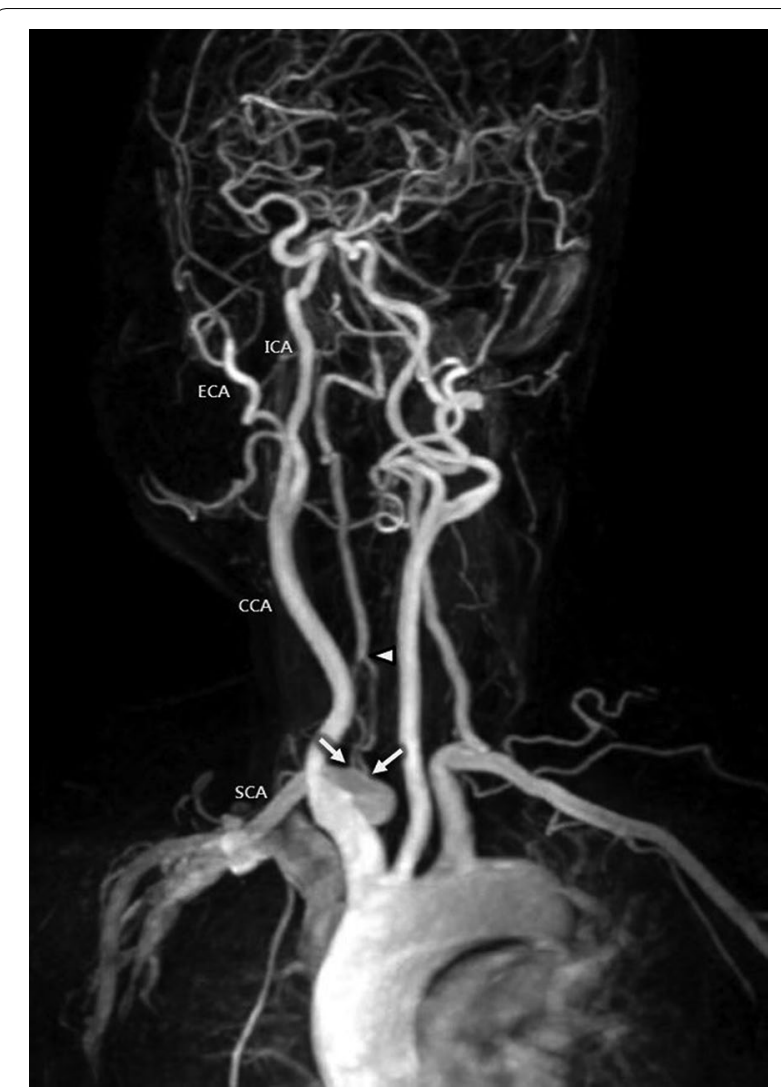

Fig. 1 3D TOF MRA of duplicated right VA. 3D time-of-flight (TOF) magnetic resonance angiography (MRA) of left oblique view shows the duplicated ostia on the right subclavain artery (arrows). Two limbs of right vertebral artery (VA) united to form the distal part of the right VA (arrowhead)

converged to form one main trunk at the $3.6 \mathrm{~cm}$ distal from each orifice. The first and second limbs of duplicated V1 segment measured 2.8 and $2.6 \mathrm{~mm}$ in diameter at the points of origin, respectively. The distance between two limbs calculated $8.0 \mathrm{~mm}$. The diameter of the common trunk of right VA was $3.8 \mathrm{~mm}$ at the point of reconstitution. On the left side, the VA arose from the left SCA and measured $4.1 \mathrm{~mm}$ in diameter. There was no other vascular abnormality in the major cervical arteries. The patient was managed conservatively and the patient's clinical symptoms were relieved after 7 days.

\section{Discussion}

Duplicated VA is a rare vascular variant (Bergman et al. 1988). It is defined that VA has two origins with fusion at a variable level of the neck. Duplication of the VA has been confused with fenestration of VA, which is a different condition showing a single origin with a short segment of two limbs of VA and one connection with each other along its course (Goddard et al. 2001; Thomas et al. 2008).
Embryologically, the VA is formed by the development of postcostal longitudinal anastomosis which links the intersegmental arteries. The intersegmental arteries eventually obliterated with an exception of the seventh, which becomes the proximal SCA and includes the VA point of origin in adults (Newton and Mani 1974). Duplication of VA is a result from abnormality of embryologic development of aortic arch and persistence of the intersegmental artery (Polguj et al. 2013a). Whereas dual origin of VA originating from the right SCA or brachiocephalic artery occurs due to persistence of the right fourth or fifth (or less frequently third) intersegmental arteries, persistence of the left fourth or fifth (or less frequently third) intersegmental arteries can result in aortic origin or dual origin of the left VA (Komiyama et al. 1999). In addition, the level of entrance into the transverse foramen indicates which intersegmental artery or arteries persist (Meila et al. 2012).

To our best knowledge, only fourteen cases have been reported the duplicated VA with dual origin from SCA among total 36 reported cases of duplicated VA (Table 1) (Babin and Haller 1974; Harada et al. 1987; Hashimoto et al. 1987; Mahmutyazicioğlu et al. 1998; Goddard et al. 2001; Ionete and Omojola 2006; Harnier et al. 2008; Mordasisni et al. 2008; Thomas et al. 2008; Meila et al. 2012; Melki et al. 2012; Polguj et al. 2013b; Rameshbabu et al. 2014). Unilateral duplication of VA was more commonly observed in left side (Goddard et al. 2001). In most cases, the two limbs of the duplicated VA arise from the aorta and the SCA. The limb of duplicated artery also can be originated from common carotid artery, brachiocephalic trunk, or thyrocervical trunk (Bergman et al. 1988; Rameshbabu et al. 2014). Generally, the normal VA is the 1st vessel branching of the SCA and it contributes to the posterior circulation of the head and neck. Whereas normal VA almost always enters the C6 transverse foramen, duplication of VA usually enters the higher transverse foramen (Thomas et al. 2008).

The clinical feature of the duplication of the VA is nonspecific and usually asymptomatic. And it is still controversy whether duplication of the VA is associated with other pathologic conditions. Ionete and Omojola (2006) demonstrated that duplicated VA was normal variation as incidental finding with no significant clinical or pathologic consequences. Conversely, anecdotal reports stated this vascular variant may predispose the patient to VA dissection, intracranial aneurysm, kinking, and arteriovenous malformation (Rameshbabu et al. 2014).

Dual origin of the VA is usually diagnosed as an incidental finding that occurs during imaging workups for other clinical situations. However, a detailed knowledge of this variation is potentially important to prevent inadvertent diagnostic or therapeutic challenges during 


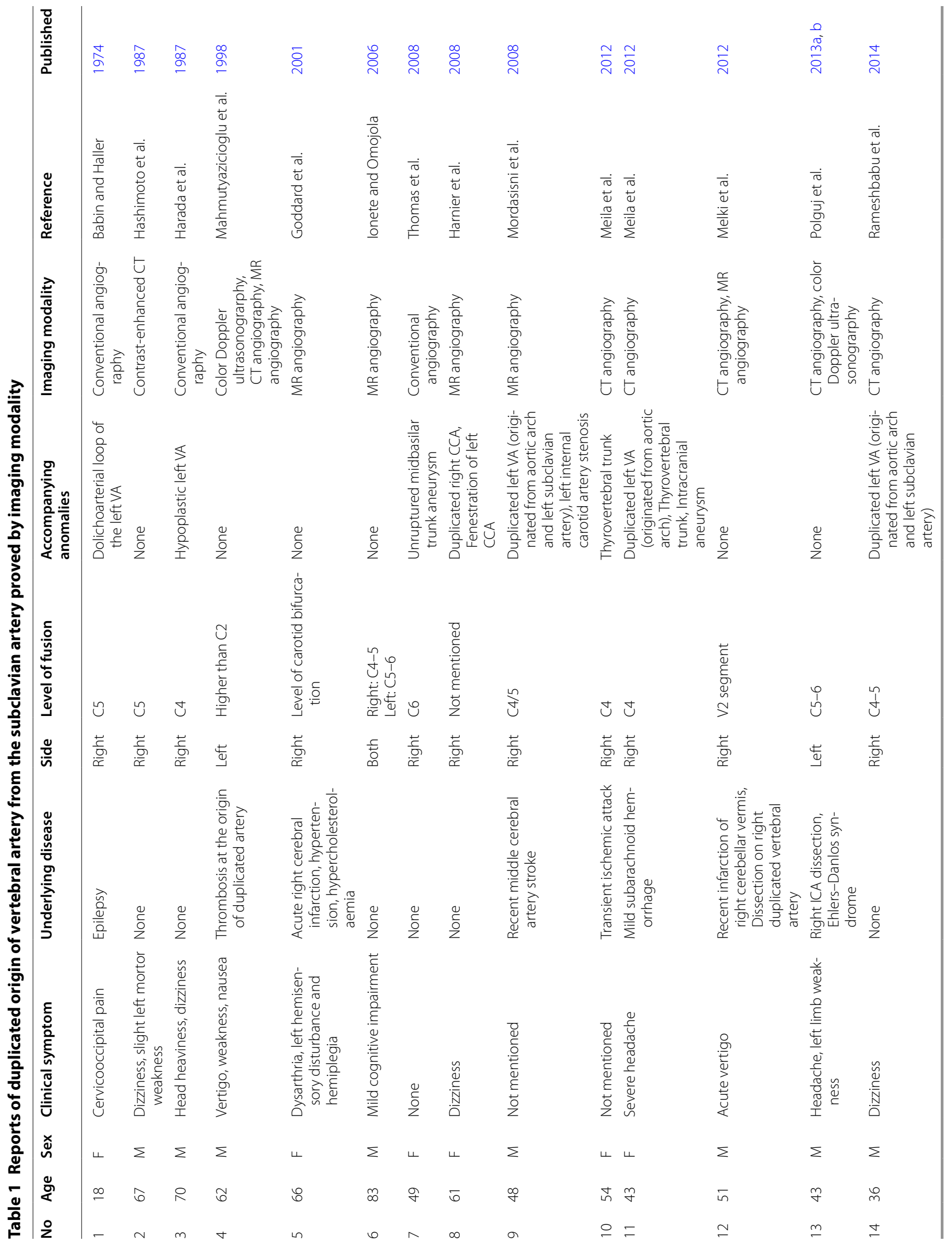


endovascular procedure. Because duplicated VA has smaller lumen of its proximal V1 than that of normal side, it can be influence the choice or route of endovascular treatment (Thomas et al. 2008; Ionete and Omojola 2006).

\section{Conclusion}

In conclusion, we provide a rare case of the right VA with dual origin as an incidental finding on MRA. This report suggested that the awareness of embryologic background about VA can be helpful to identify unexpected vascular findings on computed tomographic angiography (CTA) or MRA, and differentiate this variation from other pathologic conditions such arterial dissection in clinical practice.

\section{Abbreviations}

VA: vertebral artery; SCA: subclavian artery; MRA: magnetic resonance angiography; MRI: magnetic resonance image; TOF: time-of-flight; CTA: computed tomographic angiography.

\section{Authors' contributions}

Concept and design: HJB, KHC. Acquisition of data: JB. Analysis and interpretation of data: HJB, JB, HSS. Drafting the manuscript: HJB, JB. Final approval: JB, HJB, HSS, KHC. All authors read and approved the final manuscript.

\begin{abstract}
Author details
1 Department of Radiology, Inje University College of Medicine, Haeundae Paik Hospital, 875 Haeundae-ro, Haeundae-gu, Busan 48108, Republic of Korea. ${ }^{2}$ Department of Radiology, Gyeongsang National University School of Medicine and Gyeongsang National University Changwon Hospital, 11 Samjeongja-ro, Seongsan-gu, Changwon 51472, Republic of Korea. ${ }^{3}$ Department of Radiology, Gyeongsang National University School of Medicine and Gyeongsang National University Hospital, 79 Gangnam-ro, Jinju 52727, Republic of Korea. ${ }^{4}$ Department of Thoracic and Cardiovascular Surgery, Research Institute for Convergence of Biomedical Science and Technology, Pusan National University Yangsan Hospital, 20 Geumo-ro, Mulgeum-eup, Yangsan 50612, Republic of Korea.
\end{abstract}

\section{Acknowledgements}

None.

\section{Competing interests}

The authors declare that they have no competing interests.

\section{Consent for publication}

Informed consent for publication of this report and any accompanying images was obtained from the patient.

Received: 29 January 2016 Accepted: 11 July 2016

Published online: 19 July 2016

\section{References}

Babin E, Haller M (1974) Correlation between bony radiological signs and dolichoarterial loops of the cervical vertebral artery. Neuroradiology 7(1):15-17

Bergman RA, Thompson SA, Afifi AK, Saadeh FA (1988) Compendium of human anatomic variation: text, atlas and world literature. Urban and Schwarzenberg, Baltimore, pp 71-72, 358-359
Goddard AJ, Annesley-Wiliams D, Guthrie JA, Weston M (2001) Duplication of the vertebral artery: report of two cases and review of the literature. Neuroradiology 43(6):477-480

Harada J, Nishijima M, Yamatani K, Endo S, Takaku A (1987) A case of the duplicate origin of right vertebral artery. No Shinkei Geka 15(3):321-325

Harnier S, Harzheim A, Limmroth V, Horz R, Kuhn J (2008) Duplication of the common carotid artery and the ipsilateral vertebral artery with a fenestration of the contralateral common carotid artery. Neurol India 56(4):491-493

Hashimoto H, Ohnishi H, Yuasa T, Kawaguchi S (1987) Duplicate origin of the vertebral artery: report of two cases. Neuroradiology 29(3):301-303

Ionete C, Omojola MF (2006) MR angiographic demonstration of bilateral duplication of the extracranial vertebral artery: unusual course and review of the literature. AJNR Am J Neuroradiol 27(6):1304-1306

Komiyama M, Nakajima H, Yamanaka K, Iwai Y (1999) Dual origin of the vertebral artery_case report. Neurol Med Chir (Tokyo) 39(13):932-937

Mahmutyazicioğlu K, Saraç K, Bölük A, Kutlu R (1998) Duplicate origin of left vertebral artery with thrombosis at the origin: color doppler sonography and CT angiography findings. J Clin Ultrasound 26(6):323-325

Meila D, Tysiac M, Petersen M et al (2012) Origin and course of the extracranial vertebral artery: CTA findings and embryologic considerations. Clin Neuroradiol 22(4):327-333

Melki E, Nasser G, Vandendries C, Adams D, Ducreux D, Denier C (2012) Congenital vertebral duplication: a predisposing risk factor for dissection. J Neurol Sci 314(1-2):161-162

Mordasisni P, Schmidt F, Schroth G, Remonda L (2008) Asymmetrical bilateral duplication of the extracranial vertebral arteries: report of a unique case. Eur J Radiol Extra 67:e91-e94

Newton TH, Mani RL (1974) The vertebral artery. In: Newton TH, Potts DG (eds) Radiology of skull and brain. Mosby, St. Louis, pp 1659-1672

Polguj M, Podgórski M, Jędrzejewski K, Topol M, Majos A (2013a) Fenestration and duplication of the vertebral artery: the anatomical and clinical points of view. Clin Anat 26(8):933-943

Polguj M, Jędrzejewski K, Topol M, Wieczorek-Pastusiak J, Majos A (2013b) Duplication of the left vertebral artery in a patient with dissection of the right internal carotid artery and Ehlers-Danlos syndrome: case report and review of the literature. Anat Sci Int 88(2):109-114

Rameshbabu C, Gupta OP, Gupta KK, Qasim M (2014) Bilateral asymmetrical duplicated origin of vertebral arteries: multidetector row CT angiographic study. Indian J Radiol Imaging 24(1):61-65

Thomas AJ, Germanwala AV, Vora N et al (2008) Dual origin extracranial vertebral artery: case report and embryology. J Neuroimaging 18(2):173-176

Watanabe K, Saga T, Iwanaga J, Tabira Y, Yamaki KI (2015) A rare case of dual origin of the left vertebral artery without convergence. Folia Morphol (Warsz) 75(1):136-142

\section{Submit your manuscript to a SpringerOpen ${ }^{\circ}$ journal and benefit from:}

- Convenient online submission

- Rigorous peer review

- Immediate publication on acceptance

- Open access: articles freely available online

- High visibility within the field

- Retaining the copyright to your article

Submit your next manuscript at $\boldsymbol{\nabla}$ springeropen.com 